\title{
EVALUATION OF ANTI-STRESS ACTIVITY OF ETHANOLIC EXTRACTS OF TERMINALIA CATAPPA L. IN SWISS ALBINO MICE
}

IMTIYAZ ANSARI, RAJESHWARI SHASHIKANT SORTE*

Department of Pharmacology, Oriental College of Pharmacy, Sanpada, Navi Mumbai, Mumbai - 400705, Maharashtra, India. Email: rajeshwarisorte92@gmail.com

Received: 01 February 2018, Revised and Accepted: 10 March 2018

\begin{abstract}
Objective: The aim of the study was to evaluate the anti-stress activity of ethanolic extract of Terminalia catappa L. in Swiss albino mice.

Methods: The extract used in this study was prepared by Soxhlet extraction of fresh dried leaves of T. catappa L. using ethanol as an extraction solvent. Stress is involved in the pathogenesis of a variety of diseases including hypertension, peptic ulcer, immunodepression, reproductive dysfunction, and behavior disorder. Overload of stress increases free radicals, produces damage to neuronal receptors and a variety of tissues. In this experimental research study two models, namely, forced swim test (FST) and tail suspension test (TST) were used for the screening of anti-stress activity. 50, 100, and $200 \mathrm{mg} / \mathrm{kg}$ ethanolic extracts of T. catappa L. were given orally, while $2 \mathrm{mg} / \mathrm{kg}$ of Diazepam which acts as a standard was given intraperitoneally.
\end{abstract} The data obtained were analyzed by one-way ANOVA, followed by Dunnett's test. $\mathrm{p}<0.05$ was considered to be significant.

Result: The entire three test groups of the ethanolic extract of leaves of T. catappa L. showed decrease in immobility time in both FST (immobility for $42.5 \pm 3.5 \mathrm{~s}$ and mobility at $197.5 \pm 3.5 \mathrm{~s}$ ) against diazepam (immobility $82.6 \pm 4.17 \mathrm{~s}$ and mobility at $157.3 \pm 4.17 \mathrm{~s}$ ) and TST ( $92 \pm 2.28 \mathrm{~s}$ and mobility at $148 \pm 2.28)$ when compared against control as well as against diazepam $(116.3 \pm 2.73 \mathrm{~s}$ and mobility at $123.6 \pm 2.73)$ which was used as a standard.

Conclusion: There is substantial evidence that flavonoids play an active role in providing anti-stress activity. This study is an attempt to find out the alternative medication for treating chronic stress with single medication which was shown a beneficial effect in animal models, may be useful for curing symptoms of stress.

Keywords: Anti-stress, Terminalia catappa L., Forced swim test, Tail suspension test.

(C) 2018 The Authors. Published by Innovare Academic Sciences Pvt Ltd. This is an open access article under the CC BY license (http://creativecommons. org/licenses/by/4. 0/) DOI: http://dx.doi.org/10.22159/ajpcr.2018.v11i6.25046

\section{INTRODUCTION}

Anxiety and depression are the most frequent psychiatric conditions commonly found in today's day-to-day life. A number of the population suffers from these conditions sometimes during their life [1]. Homeostasis regulates the physiological actions in the body and depends on the stress and antioxidant levels in the cells. Stress is involved in the major portion of alterations of physiological actions, leading to pathogenesis [2]. Stress is a common phenomenon that is experienced by every individual. When stress becomes extreme, it is harmful for the body, and hence, needs to be treated. Stress is involved in the pathogenesis of a variety of diseases including hypertension, peptic ulcer, immunodepression, reproductive dysfunction, and behavior disorder [3]. Overload of stress increases free radicals, produces damage to neuronal receptors and a variety of tissues. Free radical scavenging agents may have a great potential in ameliorating these disease/disorders. Stress basically is a reaction of mind and body against change in the homeostasis. The productive stress is called eustress while harmful stress is called distress. Stress triggers a wide range of body changes called general adaptation syndrome (GAS). The stimuli, which produce GAS, are called stressors and range from physical to psychological factors including cold, heat, infection, toxins, and major personal disappointment [4].

Anti-stress agents decrease stress. Considering the debut of adaptogens, many plants have been explored due to their anti-stress and renovating properties in conventional medicines [5]. Drugs having anti-stress properties induce a state of non-specific resistance against the stressful condition. Drugs like benzodiazepines certain central nervous system (CNS) stimulants such as amphetamines and caffeine as well as some anabolic steroids are routinely used by people to combat stress. The incidence of toxicity and dependence has limited the therapeutic usefulness of these drugs [6]. Alternative is clearly needed because of the inability of the current therapies to manage the condition of disease [7]. The first drug used to treat pathologic condition of the CNS was based on natural resources [8]. Peoples from different areas of world use herbal medicine to alleviate affective disorders [9]. In Mexico, several medicinal plants are used to alleviate insomnia, depressed mood, and anxiety [10]. The herbal formulations claimed to enhance physical endurance; mental functions and non-specific resistance of the body have been termed as adaptogens [11].

Terminalia catappa L. family Combretaceae also known as Indian almond is a large tree that grows in tropical countries with a maximum height of $35 \mathrm{~m}$, being upright, with horizontal branches and symmetrical crown [12]. Its trunk is $1-1.5 \mathrm{~m}$ in diameter, frequently buttressed at the base, the leaves were obovate and alternate between one another, petioles are short, spirally gathered at the branch tips, the leaves are dark green above, paler underneath, glossy, and or leathery. Sometimes change to bright scarlet, yellow, dark red, and/or dark purple. These trees are distributed throughout the tropics in costal environments in India. The dried leaves are used for fish pathogen treatment, as a substitute to antibiotics. The leaves of the plant contain ellagic acid, corilagin, Gallic acid, and flavonoids (kaempferol and quercetin) compound in rich quantity antioxidant as well as anticlastogenic properties [13,17-19]. The antioxidant properties of flavones allow them to demonstrate potential application as protective and attenuating agents in oxidative stress. Hence, the present study was undertaken to inspect the anti-stress potential of flavonoids from the leaves of T. catappa L. 


\section{METHODS}

\section{Collection and authentication of plant materials}

Fresh leaves of T. catappa L. were collected from the Botanical Garden of Oriental College of Pharmacy Sanpada, Navi-Mumbai, Maharashtra, and were authenticated by Dr. Praveen Kale, Botanist at St. Xavier's College, Mumbai - 400001

\section{Extraction and phytochemical evaluation}

The authenticated leaves were dried under shade and then powdered with a mechanical grinder to obtain a coarse powder. Equal quantity of powder was passed through 40 mesh sieve and extracted with ethanol $(90 \% \mathrm{v} / \mathrm{v})$ in Soxhlet apparatus at $60^{\circ} \mathrm{C}$. The solvent was completely evaporated in the hot air oven. The presences of phytochemical constituents in the ethanolic extract of leaves of T. catappa L. was tested using the standard methods. Therefore, these methods revealed the presences of flavonoids.

\section{Experimental animals}

The animals used for the experiments were healthy either sex SwissAlbino mice aged 3-5 weeks (20-30 g) were procured from Bombay Veterinary College, Mumbai. The animals were group-housed in standard polypropylene cages (6 mice per cage) under good hygienic conditions in the registered animal house and maintained under controlled room temperature $\left(22 \pm 2^{\circ} \mathrm{C}\right)$ and humidity $(55 \pm 5 \%)$ with 12 -h light-dark cycle with food and water available ad libitum. All animal experiments were conducted in accordance with the CPCSEA guidelines. Efforts were made to minimize animal suffering and to use only the number of animals necessary to produce reliable scientific data. The Institutional Animal Ethics Committee of Oriental College of Pharmacy approved the experimental protocol no. OCP/IAEC/2016-2017/03.

\section{Phytochemical analysis}

Shinoda test and Lead acetate solution test are part of Test for Flavonoids.

\section{Shinoda test}

To test extracts, $5 \mathrm{ml}$ 95\% ethanol was added. Then, few drops of conc. $\mathrm{HCl}$ and $0.5 \mathrm{~g}$ magnesium turnings were added. Formation of pink color indicates the presence of flavonoids.

\section{Lead acetate solution test}

To a small quantity of test extract, lead acetate solution was added and mixture shaken. Yellow colored precipitate indicates the presences of flavonoids.

\section{Acute oral toxicity (AOT)}

The method followed to perform the AOT was the Acute Toxic Class method, i.e., OECD - 423. Three doses were chosen from the Annex-II of OECD 423, i.e., medium, minimum, and maximum, i.e. $300 \mathrm{mg} / \mathrm{kg}, 500 \mathrm{mg}$, and $2000 \mathrm{mg}$ after sighting study. A total of 9 animals were chosen, i.e. , 3 animals per group and three groups were taken, namely, T. catappa L. extract $-300 \mathrm{mg}$, $500 \mathrm{mg}$, and $2000 \mathrm{mg}$. A single dose was administered, and animals were observed for a period of 14 days for clinical signs and mortality.

\section{Selection of dose}

It was observed that at the dose of $2000 \mathrm{mg}$ of T. catappa L. Leaf extract caused death in mice. Therefore, the dose was then decreased, and further observation was carried out at the dose of $1000 \mathrm{mg}$. At this dose of administration, there was no mortality observed.

\section{Drugs}

- Drug extracts (50 mg, $100 \mathrm{mg}$, and $200 \mathrm{mg}$ )

- Diazepam

- Distilled water

\section{Dose selection}

Doses are selected as shown in Table 1.

\section{SCREENING FOR ANTI-STRESS ACTIVITY}

\section{Forced swim test (FST)}

A total number of mice were randomly divided into five groups $(n=6$ per group), namely, the normal control (Group 1), positive control (Group 2), and 3 test groups (50 mg/kg, $100 \mathrm{mg} / \mathrm{kg}$, and $200 \mathrm{mg} / \mathrm{kg}$ ), which were administered. Distilled water $(5 \mathrm{mg} / \mathrm{kg})$, diazepam (i.p.) $2 \mathrm{mg} / \mathrm{kg}$ body weight, and estimated doses 200,100 , and $50 \mathrm{mg} / \mathrm{kg}$ of ethanolic extract of T. catappa L. leaves, respectively, per os (p.o.) for a total of 7 days. On day 6, all the mice were allowed to swim individually for $6 \mathrm{~min}$ for adaptation. On day 7, the mice were allowed to swim individually for $6 \mathrm{~min}$ and the duration of immobility (period during which the mice only float in the upright position with minimum movement to keep their heads above water) was scored 4 min after placement into the water [15].

\section{Tail suspension test (TST)}

After Weighing and numbering the animals were divided into five groups each containing 6 mice. First group was of normal control, second group of positive control, and third groups of test substances. Animals were suspended individually by the end of tail with micropore adhesive tape (approximately $1 \mathrm{~cm}$ ) with the head $50 \mathrm{~cm}$ from the bottom. Mice were suspended for a total of $6 \mathrm{~min}$. During the final $4 \mathrm{~min}$ interval of the test, duration of immobility was recorded. Mice were considered immobile only when they will be hung passively and completely motionless [16]. There are also differences between the FST and the TST in their ability to differentiate classes of anti-stress. Traditionally, it was presumed that selective serotonin reuptake inhibitors (SSRIs) do not have antistress-like effects in the FST, but SSRIs have been shown to be effective in TST. Anti-stress decreases the immobility of mice in these tests. Furthermore, stressors such as immobilization, foot shock, and social defeat increases the depression-like behavior in the FST.

Statistical analysis

All values are expressed as mean \pm SD. Statistical significance was determined using one-way ANOVA, followed by Dunnett's test. $\mathrm{p}<0.05$ was considered to be significant.

\section{RESULTS}

Phytochemical analysis

The phytochemical analysis of extract revealed the presence of flavonoids in the leaves of T. catappa $\mathrm{L}$.

\section{AOT study}

The results of these studies are as follows.

\section{Mortality}

The extracts were found to be unsafe at a dose of $2000 \mathrm{mg} / \mathrm{kg}$ since mortality was observed. Therefore, the dose was decreased to $1000 \mathrm{mg} / \mathrm{kg}$ and the mortality was not observed.

\section{Signs and symptoms of toxicity}

Signs of intoxication were not observed $24 \mathrm{~h}$ post-treatment as dose did not produce any significant changes in behavioral pattern and failed to elicit any clinical abnormality. LD50 was considered as more than $1000 \mathrm{mg} / \mathrm{kg}$. Results of AOT are shown in Table 2 .

FST

The entire three test groups of the ethanolic extract of leaves of T. catappa L. showed dose-dependent decrease in immobility time when compared against control as well as against diazepam which was used as a standard. Results of FST are shown in Table 3 and Fig. 1.

TST

All the three test doses of the ethanolic extract of leaves of T. catappa $\mathrm{L}$. showed dose-dependent decrease in immobility time when it was compared against control as well as against diazepam which was used as a standard. Results of TST are shown in Table 4 and Fig. 2. 


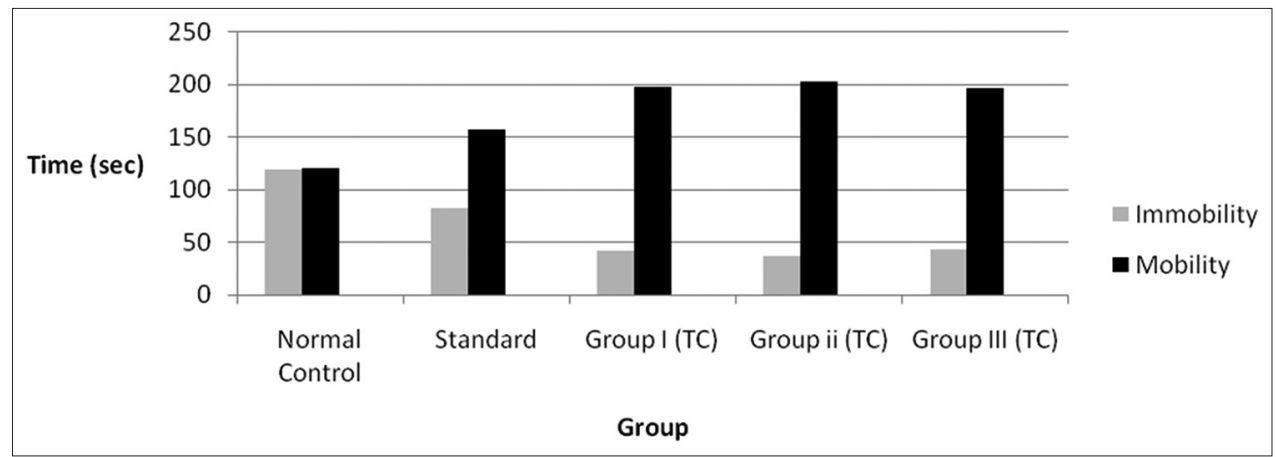

Fig. 1: Effect of Terminalia catappa L. on mobility and immobility time of forced swim test in mice

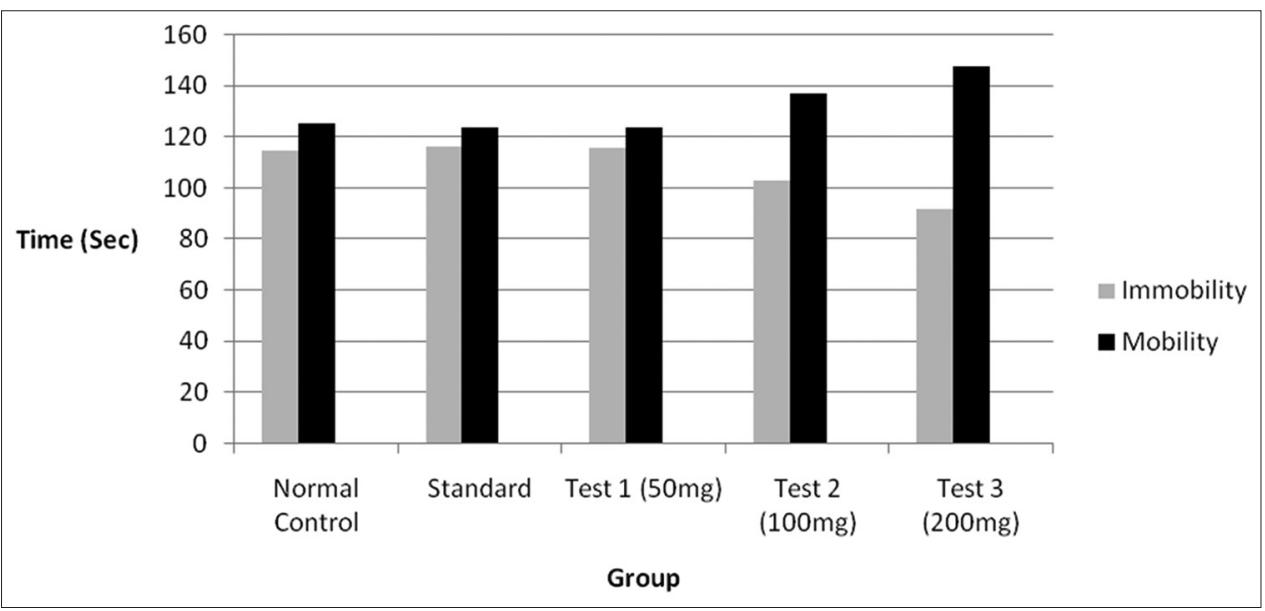

Fig. 2: Effect of Terminalia catappa L. on mobility and immobility time of tail suspension test in mice

Table 1: Grouping of animals and dose selection

\begin{tabular}{ll}
\hline Treatment & Dose \\
\hline Normal control (distilled water) & $5 \mathrm{mg} / \mathrm{kg}$ (p.o.) \\
Standard control (diazepam) & $2 \mathrm{mg} / \mathrm{kg}$ (i.p.) \\
Test 1: T. catappa L. (TC) & $50 \mathrm{mg} / \mathrm{kg}$ (p.o.) \\
Test 2: T. catappa L. (TC). & $100 \mathrm{mg} / \mathrm{kg}$ (p.o.) \\
Test 3: T. catappa L. (TC). & $200 \mathrm{mg} / \mathrm{kg}$ (p.o.) \\
\hline T. catappa: Terminalia catappa &
\end{tabular}

Table 2: Acute toxicity testing of ethanolic extract of T. catappa L. in mice

\begin{tabular}{ll}
\hline Parameter & Ethanolic extract of T. catappa $\mathbf{L}$. \\
\hline 1.Loss of reflex & \\
Righting reflex & - \\
Pinna reflex & - \\
Corneal reflex & - \\
2. Changes in the bw, skin, & - \\
and fur & \\
3. Any clinical abnormalities & - \\
Tremors & - \\
Convulsions & - \\
Salivation & - \\
Diarrhea & - \\
Lethargy & - \\
Sleep & - \\
Coma & \\
4. Death within & + \\
24 h & + \\
1-14 days & \\
\hline Bw: Body weight, T. catappa: Terminalia catappa
\end{tabular}

Bw: Body weight, T. catappa: Terminalia catappa
Table 3: Effect of T. catappa L. on mobility and immobility time of FST in mice

\begin{tabular}{llll}
\hline Treatment & Dose & Immobility (s) & Mobility (s) \\
\hline $\begin{array}{l}\text { Normal control } \\
\text { (distilled water) }\end{array}$ & $5 \mathrm{mg} / \mathrm{kg}$ (p.o.) & $119 \pm 2.36$ & $121 \pm 2.36$ \\
$\begin{array}{l}\text { Standard control } \\
\text { (diazepam) }\end{array}$ & $2 \mathrm{mg} / \mathrm{kg}$ (i.p.) & $82.6 \pm 4.17$ & $157.3 \pm 4.17$ \\
Test 1: T. catappa L. & $50 \mathrm{mg} / \mathrm{kg}$ (p.o.) & $43 \pm 5.40$ & $197 \pm 5.40$ \\
$\begin{array}{l}\text { Test 2: T. catappa L. } 100 \mathrm{mg} / \mathrm{kg} \text { (p.o.) } \\
\text { Test 3: T. catappa L. } 200 \mathrm{mg} / \mathrm{kg} \text { (p.o.) }\end{array}$ & $42.5 \pm 4.03$ & $203.5 \pm 4.03$ \\
\hline
\end{tabular}

Table 4: Effect of T. catappa L. on mobility and immobility time of TST in mice

\begin{tabular}{llll}
\hline Treatment & Dose & Immobility (s) & Mobility (s) \\
\hline $\begin{array}{l}\text { Normal control } \\
\text { (distilled water) }\end{array}$ & $5 \mathrm{mg} / \mathrm{kg}$ (p.o.) & $114.6 \pm 2.87$ & $125.3 \pm 2.87$ \\
$\begin{array}{l}\text { Standard control } \\
\text { (diazepam) }\end{array}$ & $2 \mathrm{mg} / \mathrm{kg}$ (i.p.) & $116.3 \pm 2.73$ & $123.6 \pm 2.73$ \\
Test 1 T. catappa L. & $50 \mathrm{mg} / \mathrm{kg}$ (p.o.) & $116 \pm 4.42$ & $124 \pm 4.42$ \\
Test 2 T. catappa L. & $100 \mathrm{mg} / \mathrm{kg}$ (p.o.) & $103 \pm 3.40$ & $137 \pm 3.40$ \\
Test 3 T. catappa L. & $200 \mathrm{mg} / \mathrm{kg}$ (p.o.) & $92 \pm 2.28$ & $148 \pm 2.28$ \\
\hline
\end{tabular}

TST: Tail suspension test, T. catappa: Terminalia catappa

\section{DISCUSSION}

Medicinal plants are widely used by the population of developing countries as alternative therapy because they are the potential sources of bioactive agents. In India, hundreds of plants are used traditionally 
for the management of various chronic diseases, but unfortunately, only a few of such medicinal plants have been made to evaluate the role of medicinal plants for their potential pharmacological activities in experimental mice and rats.

The treatment mainly focused in the management of stress which in a link to another chronic disease (stress and diabetes). Stress is associated to activate the hypothalamic-pituitary-adrenal axis, resulting in the release of corticotrophin releasing hormone ( $\mathrm{CRH}$ ) from the hypothalamic periventricular nucleus. CRH causes the anterior pituitary to secrete an adrenocorticotropic hormone, which in turn stimulates the adrenal cortex to secrete corticosterone, which due to its lipophilic nature easily enters the brain. Within the brain, the hormone acts at those sites where corticosteroid receptors are expressed such as in limbic areas. Noradrenaline and corticosterone, stress exposure also leads to enhanced release of neuropeptides in the brain, such as vasopressin and $\mathrm{CRH}$.

Phytochemical analysis of the leaves of T. catappa L. has shown the presence of flavonoids. It has been seen that there is a direct relation between the flavonoids and their anti-stress activity. At the initiation, to estimate the CNS profile of the test plant extract, they were screened in several preliminary behavioral animal models such as FST and TST. Significant reduction is an indication of its stress action while excessive reduction may indicate neurotoxicity too. Hence, it is advisable to check the degree of the change in these parameters on administration of the drug. The FST or despair swim test and TST are most widely used for the evaluation of anti-stress property of novel compounds.

In FST, mice were forced to swim in a restricted space from which there was no escape, and will, after periods of agitation, cease attempts to escape and become immobile. It is accepted that immobility seen in rodents during swimming reflects behavior despair as seen in human depression and that the anti-stress drugs are able to reduce the immobility time in mice. In swimming endurance test, in swimming endurance test, animal forced to swim in water eventually assume a characteristic immobile posture which reflects a state of tiredness, fatigue reduced stamina, or depressed mood. These signs represent the core symptoms observed in depressed patients and an individual under intense stress. Drugs with anti-stress property reduce the duration of immobility in animals. It has been well-demonstrated that drugs with anti-stress activity increase swimming endurance.

Results of the swimming endurance test indicate clearly that the leaves have the properties, whereby, they increase the physical endurance as well as the overall performance in mice. All three doses showed dosedependent decrease in immobility time in swimming endurance test, and thus, further supports its anti-stress potential. This ensures that any increase in mobility observed in the FST, after treatments.

The TST has been described by Cryan et al. (2005) as a facile means of evaluating potential anti-stress. The immobility displayed by rodents when subjected to unavoidable and inescapable stress has been hypothesized to reflect behavioral despair, which in turn may reflect depressive disorders in humans. Clinically effective anti-stress reduce the immobility that mice display after active and unsuccessful attempts to escape when suspended by tail.

It was observed that there was a decrease in the immobility of the test dose compared to the test dose. Results of the swimming endurance test indicate clearly that the leaves have the properties, whereby, they increase the physical endurance as well as the overall performance in mice. All three doses showed dose-dependent decrease in immobility time in swimming endurance test, and thus, further supports its antistress potential.

It was observed from the results that the leaves of T. catappa L. showed significant $(\mathrm{p}<0.0001)$ dose-dependent decrease in the immobility time in FST and TST when compared with the control group.
This implies that it contains active chemical constituents to elicit specific types of behavior in TST and FST through noradrenergic, serotonergic, and dopaminergic systems and thereby acting as an anti-stress agent. It also suggests that the activation of these systems may depend on the concentration of the extract. Further, there was no remarkable change in the ambulatory behavior on the chronic treatment of all the extracts at said dose levels. The ambulatory behavior decreased in comparison to the control group, but no significant difference was found

\section{CONCLUSION}

There is substantial evidence that flavonoids play an active role in providing anti-stress activity. This study is an attempt to find out the alternative medication for treating chronic stress with single medication which was shown a beneficial effect in animal models, may be useful for curing symptoms of stress.

\section{ACKNOWLEDGMENT}

Authors are thankful to Prof. (Dr.) Mrs. Sudha Rathod, Principal of Oriental College of pharmacy, Sanpada, Navi Mumbai, India, providing all the facilities for this research project. We are also thankful to Dr. (Mrs) Vanita Kanase and Dr. Sayyed Mateen for the constant support and guidance. Special thanks to the teaching and non-teaching staff of Oriental College of Pharmacy.

\section{AUTHORS CONTRIBUTION}

We declare that this work was done by the authors named in this article and all liabilities pertaining to claims relating to the content of this article will be borne by the authors. Drx (Ms.) Rajeshwari Sorte collected the data, analyzed the data, all the laboratory work performed, wrote the introduction, discussion and the material and method part. Mr. Imtiyaz Ansari proof-read the whole manuscript as well as helps in designing and conducting the study.

\section{CONFLICTS OF INTEREST}

The authors declare that there are no conflicts of interest regarding the publication of this paper.

\section{REFERENCES}

1. Selvi PT, Kumar SM, Kathiravan T, Rajesh R, Megala J, Sravani S. Antistress activity of aqueous extract of leaves of Centella asiatica Linn by in vivo methods. Asian J Res Pharm Sci 2012;2:91-4.

2. Kilari EK, Rao LS, Sreemanthula S, Kola PK. Anti-stress and nootropic activity of aqueous extract of Piper longum fruit, estimated by noninvasive biomarkers and Y-maze test in rodents. Environ Exp Biol 2015;13:25-31.

3. Tiwari N, Mishra A, Bhatt G, Chaudhary A. Anti stress activity (in-vivo) of forskolin isolated from Coleus forskohlii. Int J Pharm Phytopharmacol Res 2014:4:201-4.

4. Selye H. The evolution of stress concept. Am Sci 1973;61:693-9.

5. Lee S, Rhee D. Effects of ginseng on stress-related depression, anxiety, and the hypothalamic-pituitary-adrenal axis. J Gins Res 2017;41:589-94.

6. Desai SK, Desai SM, Navdeep S, Arya P, Pooja T. Antistress activity of Boerhaavia diffusa root extract and a polyherbal formulation containing Boerhaavia diffusa using cold restraint stress model. Int J Pharm Pharm Sci 2011;3:130-2.

7. Marles RJ, Farnswort N. Antidiabetic plants and their active constituents. Phytomedicine 1995;2:137-89.

8. Gomes NG, Campos MG. Plants with neurobiological activity as potential targets for drug discovery. Prog Neuro Psychopharmacol Boil Psychi 2009;33:1372-89

9. Mora S, Millan R. The hydroalcoholic extract of Salvia elegans induces anxiolytic and antidepressant like effects in rats. J Ethnopharmacol 2009;106:76-81.

10. Zolla C. Traditional medicine in Latin America with particular reference to Mexico. J Ethnopharmacol 1980;2:37-41.

11. Anssari M, Fasiuddin M, Salman S, Nazer S, Imran M, Toufeeq M, et al. Pharmacological screening of polyherbal formulation for anti stress activity on albino rats. Int $J$ Pha Res 2015;5:125-8.

12. Owolabi MS, Lawal OA, Ogunwande IA, Hauser RM, Setzer WN. 
Chemical composition of the leaf essential oil of Terminalia catappa L. growing in southwestern Nigeria. Am J Essent Oils Nat Prod 2013;1:51-4.

13. Masuda T, Yonemori S, Oyama Y, Tekeda Y. Evaluation of antioxidant activity of Environmental plants activity of the leaf extracts from sea shore plants. J Agric Food Chem 1999;47:1749-54

14. Khandelwal KR. Practical Pharmacognosy Techniques and Experiments. Pune: Niraliprakashan; 2010.

15. Patil R, Ahirwar B, Ahirwar D. Current status of Indian medicinal plants with ant diabetic potential: A review. Asian Pac J Trop Biomed 2011;2:S291-8.

16. Gajarmal AA, Shende MB, Chothe DS. Antistress activity od
Ashwagandha (Withania somnifera Dunal) - A Review. Int Ayurvedic Med J 2014;2:386-93.

17. Lotankar AR, Wankhede S, Sharma JB, Momin AJ. Anti-stress activity of flavonoids rutin and Quercetin isolated from the leaves of Ficus benghalensis. Int J Pharm Pharm Res 2016;5:5-19.

18. Neelavathi P, Venkatalakshmi P, Brindha P. Antibacterial activities of aqueous and ethanolic extracts of Terminalia catappa leaves and bark against some pathogenic bacteria. Int J Pharm Pharm Sci 2013;5:114-20.

19. Cryan, J. F. Mombereau, C. Vassout, A. The tail suspension test as a model for assessing antidepressant activity: Review of pharmacological and genetic studies in mice. Neuroscience \& Biobehavioral Reviews 2005, 29 (4-5), 571-625. 